\title{
Analysis of the characteristics and causes of coastline variation in the Bohai Rim (1980-2010)
}

\author{
Ning $\mathrm{Xu}^{1,2} \cdot$ Zhiqiang Gao $^{1} \cdot$ Jicai Ning $^{1}$
}

Received: 29 July 2015/ Accepted: 12 February 2016

(C) Springer-Verlag Berlin Heidelberg 2016

\begin{abstract}
This paper retrieved categorical mainland coastline information in the Bohai Rim from 1980, 1990, 2000 and 2010 utilizing remote sensing and GIS technologies and analyzed the characteristics and causes of the spatial-temporal variation over the past 30 years. The results showed that during the research period, the length of the coastline of the Bohai Rim increased continuously for a total increase of $1071.3 \mathrm{~km}$. The types of coastline changed significantly. The amount of artificial coastlines increased continuously and dramatically from $20.4 \%$ in 1980 to $72.2 \%$ in 2010 , while the length of the natural coastlines decreased acutely. Areas that had coastlines that changed significantly were concentrated in Bohai Bay, the south and west bank of Laizhou Bay and the north bank of Liaodong Bay. Due to the comprehensive effects of natural and anthropogenic factors, the coastline mainly expanded seaward. Coastal engineering construction were the leading factor in coastal evolution. Furthermore, the reclamation of aquaculture pond, salt field and harbor construction were the top three construction activities. Additionally, the driving force caused coastline change showed significant temporal heterogeneity.
\end{abstract}

Keywords Spatial and temporal variation - RS · GIS . DSAS

Zhiqiang Gao

zqgao@yic.ac.cn

1 Key Laboratory of Coastal Environmental Processes and Ecological Remediation, Yantai Institute of Coastal Zone Research, Chinese Academy of Sciences, Yantai 264003, China

2 University of Chinese Academy of Sciences, Beijing 100049, China

\section{Introduction}

Coastal zone is a unique environment in which atmosphere, hydrosphere and lithosphere contact each other (Alesheikh et al. 2007; Sesli et al. 2009). Furthermore, the coastal zone is a difficult place to manage, involving a dynamic natural system that has been increasingly settled and pressurized by expanding socioeconomic systems (Turner 2000). For coastal zone monitoring, coastline extraction in various times is a fundamental work (Alesheikh et al. 2007). Coastline mapping and coastline change detection become critical to coastal resource management, coastal environment protection, sustainable coastal development, and planning (Li et al. 2002).

There have been numerous studies on coastlines changes. However, the coastline extracted by many processing methods (Lee and Jurkevich 1990; Ryu et al. 2002; Liu and Jwzek 2004; Kim et al. 2007) from the satellite images is the sea-land boundary that existed at the specific time of image acquisition, namely, the instantaneous coastline ( $\mathrm{Li}$ et al. 2002; Muslim and Foody 2008), rather than the real geographical definition of the coastline (Boak and Turner 2005; Ma et al. 2007; Xu et al. 2014). This instantaneous coastline needs to be convert into a tide-coordinate coastline (Li et al. 2002). This method has limited use for historical coastline determination, unless sufficient ground control and photogrammetric coverage is available (Gens 2010).

Some scholars have carried out a great deal of research on coastline change and related scientific issues in the Bohai Rim. Zhu and Xu (2012) analyzed the annual processes of reclamation along the northwest coast of Bohai Bay from 1974 to 2010. Sun et al. (2014) analyzed the coastline change and its driving forces in Bohai Bay from 2000 to 2010. Xu et al. (2014) analyzed the characteristics 
of the spatial-temporal changes in the coastline's length and fractal dimension, relationship between the coastline length change and fractal dimension change, as well as driving forces of coastline changes in the Bohai Rim from 2000 to 2012. Overall, the researchers studied only partial regions of Bohai Rim or in short term, but not gave the whole situation of coastline change in Bohai Rim in long term.

Therefore, in accordance with the Office of the State Oceanic Administration 908 Special (2005) definition, the coastline was regarded as the line that traces the boundary between land and sea during an average high spring tide. The objectives of this study were to analyze the characteristics of the spatial-temporal variation of the coastline and its driving forces in the Bohai Rim. The visual interpretation method was employed to retrieve the coastline types, and the baseline method was applied to analyze the coastline change at four time points (1980, 1990, 2000 and 2010). This research has a reference value for scientific planning and rational utilization of coastal resources in the Bohai Rim.

The Bohai Rim (Fig. 1) situated in north China, involves Liaoning Province, Hebei Province, Tianjin Municipality and Shandong Province in this paper. This Rim may be described as a hotspot with respect to its large natural and artificial coastline changes. The coastline starts at the Yalu River Estuary in Liaoning Province and ends at the junction of Shandong Province and Jiangsu Province, which is a range from $117^{\circ} 30^{\prime} \mathrm{E}$ to $124^{\circ} 20^{\prime} \mathrm{E}$ longitude and $35^{\circ} 5^{\prime} \mathrm{N}$ to $41^{\circ} \mathrm{N}$ latitude. This rim is becoming the third largest and most important economic zone in China after the Yangtze River Delta and the Pearl River Delta. This rapidly developing economic region is thriving at a quickened pace with a large population density and a high concentration of industries (Guo et al. 2009). Meanwhile, numerous major rivers in China flow into the Bohai Sea, including the Yellow River, Haihe River, Luanhe River, Shuangtaizi River and Daliao River. Changes in natural conditions, including (but not limited to) estuarine sedimentation and erosion, and the influences of anthropogenic activities, such as coastal engineering, land reclamation, port construction, and other activities, will inevitably cause constant changes in coastlines and thereby affect the coastal environment ( $\mathrm{Xu}$ et al. 2014). Thus, it needs to be studied at a high temporal frequency.

\section{Methods}

\section{Data}

To detect coastline changes in the Bohai rim, a total of 62 multi-temporal remote sensing data of Landsat MSS/TM/ ETM + imageries captured in 1980, 1990, 2000 and 2010, were downloaded freely from Earth Resources Observation and Science (EROS) Center website (http://glovis.usgs. gov/). All of which were rectified and projected using the Universal Transverse Mercator system in the world reference system (WGS84) datum with geographical error within 0.5 pixels. Auxiliary data mainly included sea charts, topographic maps, administrative maps and statistical yearbooks. In addition, a field investigation of the coastlines in the Bohai Rim was carried out to provide significant support for the visual interpretation of the coastline type.

\section{Extraction and classification of coastline}

The coastlines are divided into mainland coastlines and island coastlines, and this paper only studied the spatialtemporal variation of the mainland coastlines in the Bohai Rim. Currently, there is no uniform standard for the classification of coastlines (Gao et al. 2013). In previous studies (Sun et al. 2011; Gao et al. 2013; Hou et al. 2014), according to whether has not been utilized, the coastlines can be divided into natural coastline and artificial coastline. Then, natural coastline can be subdivided into bedrock coastline, sandy coastline, muddy coastline, biological coastline and estuary coastline on the basis of composition and spatial pattern. Artificial coastline can be subdivided into aquaculture, salt field, cultivated field, construction, harbor, revetment and seawall, transportation and groin on the basis of functional use.

The following principles and interpretation standards were applied for determining the different types of coastline (Zhu et al. 2001; Boak and Turner 2005; Ma et al. 2007; Xu et al. 2014). (1) For bedrock coast, the locations where ocean capes and upright cliffs directly contact with seawaters were regarded as the coastline. For sandy coasts that are generally flat, sandy sediments are carried by the spring tide and often deposited to form a ridge that is parallel to the shore; the position of this ridge was regarded as the location of the coastline. For muddy coasts that have been developed or encompass a relatively small area, the coastline was regarded as the dividing line between tidal flats and other surface features, such as vegetation line, seaward of coastal engineering, because at the height of spring tide, seawater cannot cross this dividing line. For muddy coasts without artificial development, the exposed land above the average high tide line during spring tides and the tidal flat below the average high tide line during spring tides will typically be portrayed in different colors in remote sensing images; the dividing line between these two types of land was regarded as the coastline. (2) For coastal estuaries: retain the harbor-like characteristics of large estuaries; reflect the geomorphologic characteristics of sand spits, shoals, and lagoons of estuaries; manifest the 


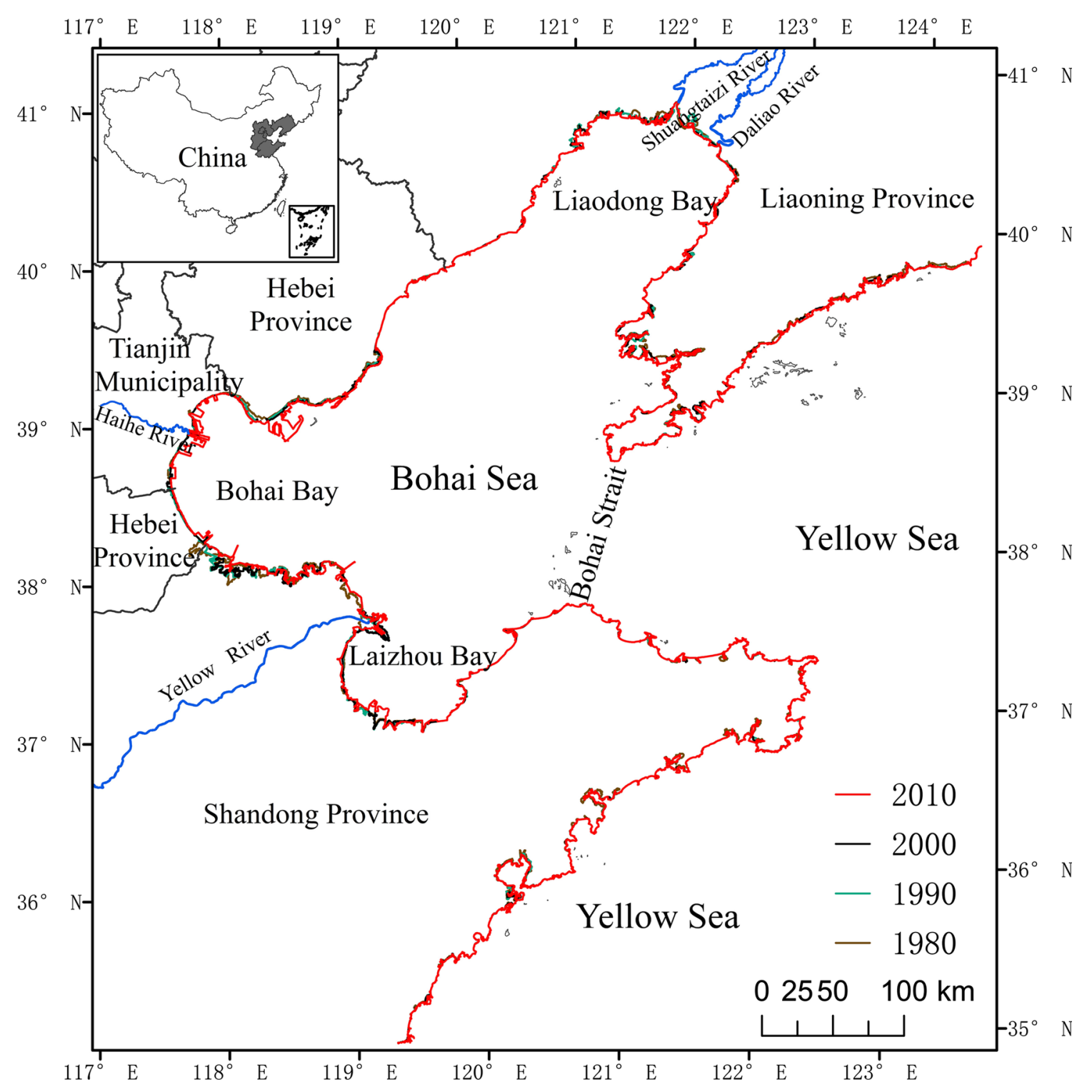

Fig. 1 The coastline distribution in the Bohai Rim from 1980 to 2010

trumpet-shaped morphology of an estuary; treat asymmetric canals based on the shapes of estuaries, assign the dividing line between estuaries to locations where rivers become narrow or the maximum curvature of capes occurs. (3) Artificial coasts directly border seawater and generally feature regular land-sea demarcation lines, like ports and enclosed embankments; the seaward side of the artificial coast was regarded as the artificial coastline. (4) The land of the tidal flats of the muddy coast (that is not submerged at high tide) was regarded as a collection of islands, and the coastlines of this land were not considered in this study.

The coastline were delineated and classified via visual interpretation by the same person at the same scale to ensure accuracy from the color composite TM/ETM +543 and MSS 432 pseudo-color image. This color composite nicely depicts water-land interface and is very similar to the true-color composite of earth's surface. Moreover, it includes the bands that have low correlation coefficient, and therefore, it contains higher information in comparison to other color composites (Moore 2000; Alesheikh et al. 2007).

In light of the low spatial resolution of MSS images in 1980 , furthermore, to ensure that the unchanged portions of the coastlines were strictly consistent in position between two consecutive periods, the coastline in 2010 was visually interpreted and digitized utilizing ArcGIS software version 10.0. Earlier coastline measurements used subsequent the coastline as the background data, and only the changed portions of coastlines were updated. As a result, this approach effectively avoided the "doublefold eyelids" 
phenomenon that would occur if the coastline dynamics had been directly extracted from remote sensing images with different spatial resolutions that had been obtained at different times (Xu et al. 2014).

\section{The method of coastline change analysis}

Quantitative analysis methods of coastline changes mainly include the baseline method, the area method, the dynamic segmentation method and the iteration method of nonlinear buffers (Thieler et al. 2009; Heo et al. 2009). The spatial variation of coastlines were analyzed using the baseline method. This method relies on image processing techniques utilizing the Digital Shoreline Analysis System, a free extension for ArcGIS software which provides a sets of tools permitting transects-based calculation of coastline displacement. The illustration of the baseline method for coastline change is shown in Fig. 2.

\section{Results}

\section{Analysis of the distribution and change of coastline types}

The distribution of coastline types in the Bohai Rim in 1980, 1990, 2000 and 2010 is shown in Fig. 3. Among the natural coastlines, bedrock coastlines were mainly distributed in headlands and bays on the Shandong Peninsula and the southern side of the Liaodong Peninsula. Muddy coastlines were located in the vicinity of the estuary of the Liaodong Bay and the Bohai-North China settlement plain area of the Bohai Bay-Yellow River Delta-south coast of Laizhou Bay. Sandy coastlines were located in the capes of bays and on both sides of the estuary. There were only a few areas of biological coastlines, which were mainly located in estuary banks such as the Liao River Estuary and the Yellow River Estuary. Large estuary deltas and plains coasts with flat topography and favorable location condition were apt to be developed, therefore, coastline development and utilization mainly originated in and expanded outwards from these areas.

As shown in Table 1, from 1980 to 2010 , due to the comprehensive effects of natural and anthropogenic factors, the total length of coastlines in the Bohai Rim increased by $1071.3 \mathrm{~km}$ in which the rates of change in 1980-1990, 1990-2000 and 2000-2010 were 0.93, 4.02 and $15.18 \%$, respectively, with a trend of accelerating growth. From 1980 to 2010, anthropogenic factors affected the coastlines of the Bohai Rim significantly. The total length of artificial coastlines increased from $1044.4 \mathrm{~km}$ in 1980, accounting for $20.4 \%$ of the total length of the coastline, to $4468.7 \mathrm{~km}$ in 2010 , accounting for $72.2 \%$ of the coastline. At the same time, the natural coastlines decreased acutely, especially the muddy coastlines and biological coastlines.

Among the types of artificial coastlines, in 1980, salt fields were the largest proportion and have changed little since then; aquaculture increased drastically from 1980 to 1990. Since 1990, aquaculture composed the greatest proportion. After 1990, its speed of growth decreased; the area of harbors increased rapidly throughout the whole period, especially after 2000. By 2010, harbors ranked second, only behind aquaculture. Construction was a low proportion of the coastline, but the growth rate increased by 2.3 times every 10 years; the growth rate of transportation reached its highest point from 2000 to 2010; cultivated fields increased significantly from 1980 to 1990 and then decreased a little; revetments and seawalls increased continuously, and the same as groins.

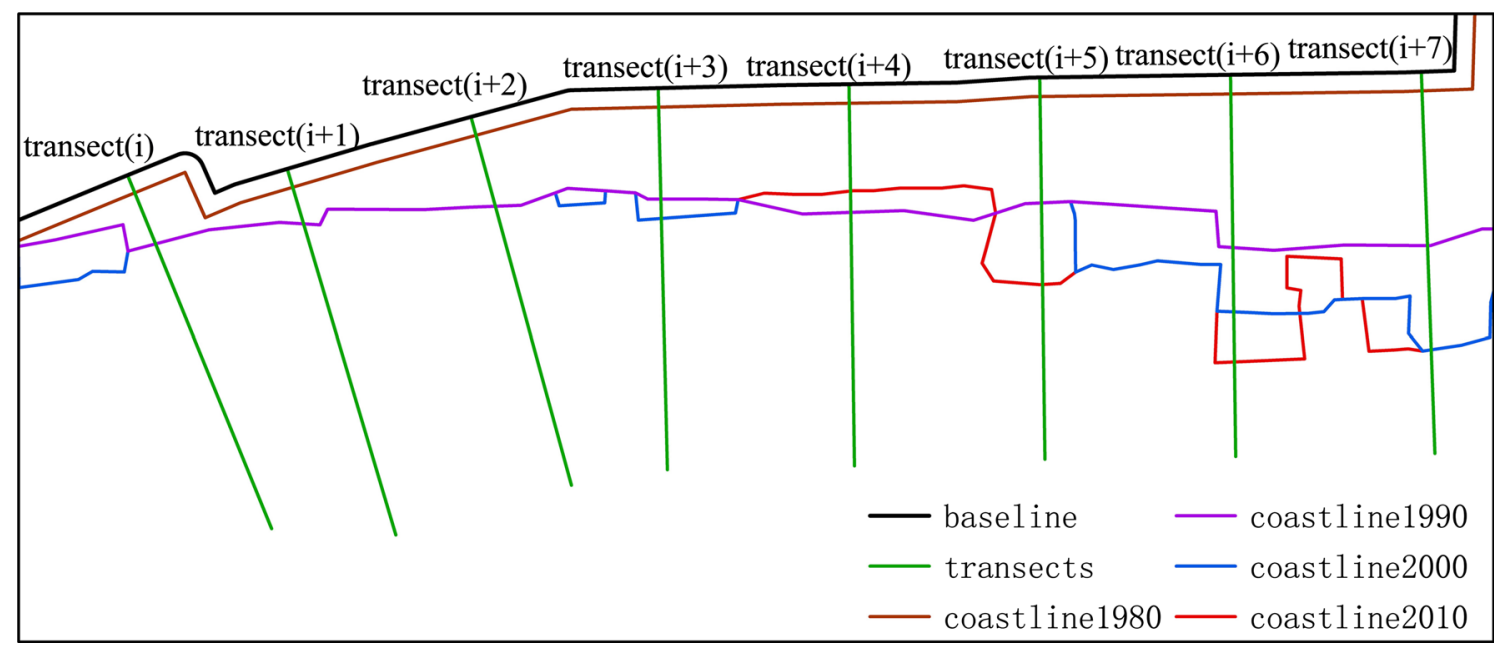

Fig. 2 Illustration of the baseline method for coastline change 


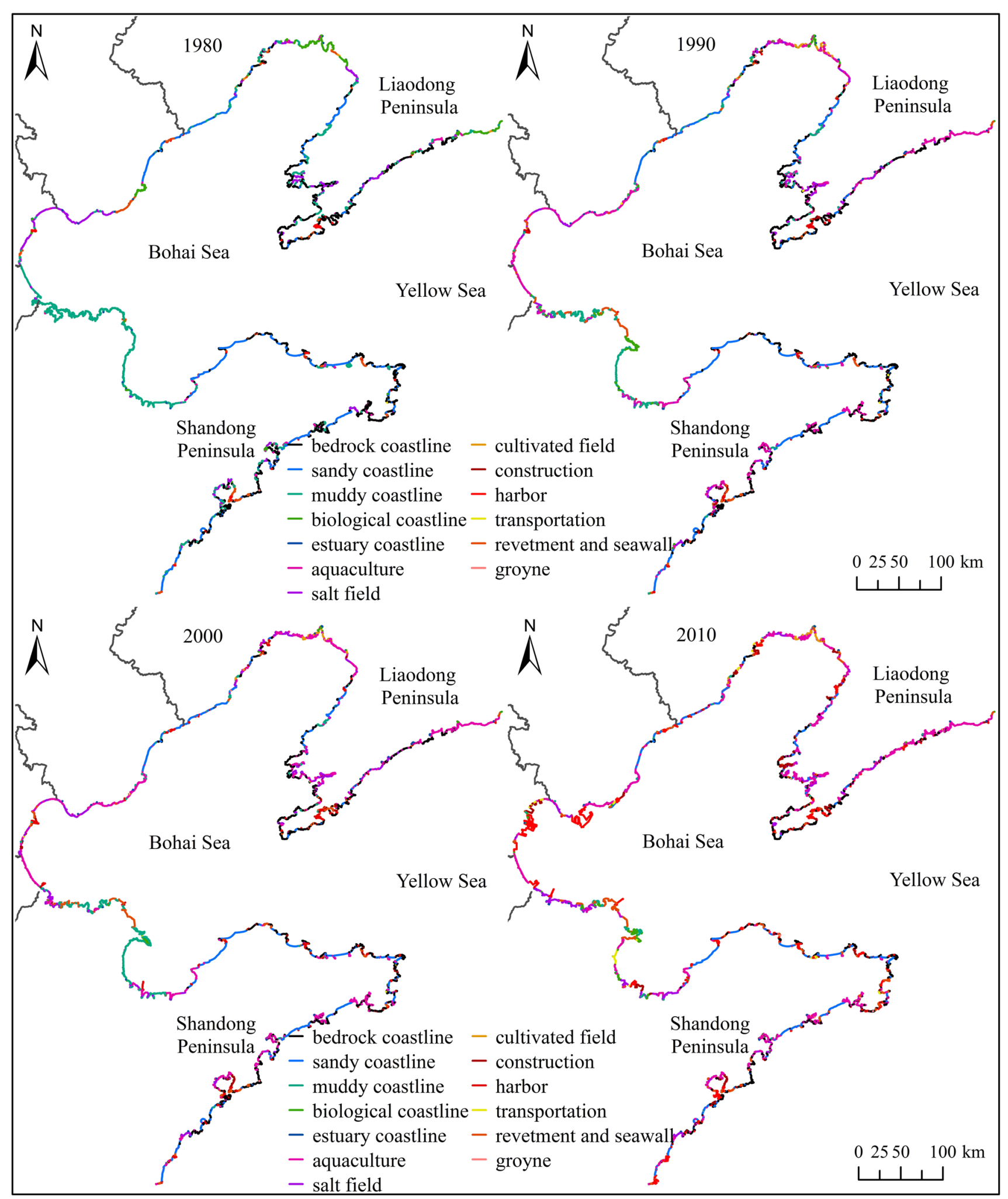

Fig. 3 Distribution of each type of coastline in 1980, 1990, 2000 and 2010

Among the natural coastline types, the proportions of bedrock coastlines and sandy coastlines decreased continuously; muddy coastlines decreased from $26.7 \%$ in 1980 to $1.8 \%$ in 2010 , during which the rate of decrease from 2000 to 2010 was the highest. Before 2000, the length and proportion of biological coastlines decreased continuously. 
Table 1 Coastline statistics in 1980, 1990, 2000 and 2010

\begin{tabular}{|c|c|c|c|c|c|c|c|c|}
\hline \multirow[t]{2}{*}{ Coastline type } & \multicolumn{4}{|c|}{ Length/km } & \multicolumn{4}{|c|}{ Proportion/\% } \\
\hline & 1980 & 1990 & 2000 & 2010 & 1980 & 1990 & 2000 & 2010 \\
\hline \multicolumn{9}{|l|}{ Natural coastline } \\
\hline Bedrock coastline & 1632.8 & 1356.5 & 1204.1 & 862.9 & 31.9 & 26.2 & 22.4 & 13.9 \\
\hline Sandy coastline & 736.5 & 697.6 & 656.1 & 556.3 & 14.4 & 13.5 & 12.2 & 9.0 \\
\hline Muddy coastline & 1366.3 & 532.8 & 580.6 & 112.7 & 26.7 & 10.3 & 10.8 & 1.8 \\
\hline Biological coastline & 324.2 & 211.9 & 57.6 & 170.5 & 6.3 & 4.1 & 1.1 & 2.8 \\
\hline Estuary coastline & 16.6 & 19.7 & 20.1 & 20.9 & 0.3 & 0.4 & 0.4 & 0.3 \\
\hline Subtotal & 4076.3 & 2818.5 & 2518.4 & 1723.3 & 79.6 & 54.5 & 46.8 & 27.8 \\
\hline \multicolumn{9}{|l|}{ Artificial coastline } \\
\hline Aquaculture & 141.5 & 1314.7 & 1451.4 & 1816.6 & 2.8 & 25.4 & 27.0 & 29.3 \\
\hline Salt field & 465.7 & 354.0 & 418.9 & 380.9 & 9.1 & 6.8 & 7.8 & 6.2 \\
\hline Cultivated field & 22.4 & 52.9 & 51.4 & 49.7 & 0.4 & 1.0 & 1.0 & 0.8 \\
\hline Construction & 12.1 & 58.2 & 134.2 & 407.0 & 0.2 & 1.1 & 2.5 & 6.6 \\
\hline Harbor & 191.5 & 308.3 & 515.9 & 1371.6 & 3.7 & 6.0 & 9.6 & 22.2 \\
\hline Transportation & 3.7 & 8.2 & 12.3 & 79.4 & 0.1 & 0.2 & 0.2 & 1.3 \\
\hline Revetment and seawall & 203.8 & 249.2 & 267.1 & 356.2 & 4.0 & 4.8 & 5.0 & 5.8 \\
\hline Groin & 3.7 & 4.4 & 6.4 & 7.3 & 0.1 & 0.1 & 0.1 & 0.1 \\
\hline Subtotal & 1044.4 & 2349.8 & 2857.6 & 4468.7 & 20.4 & 45.5 & 53.2 & 72.2 \\
\hline Total & 5120.7 & 5168.3 & 5376.0 & 6192.0 & 100 & 100 & 100 & 100 \\
\hline
\end{tabular}

After 2000, they increased significantly, but represented a decreasing trend, while estuary coastlines remained essentially unchanged.

The baseline method was used to calculate the changes and spatial distributions in the mainland coastlines in the Bohai Rim from 1980 to 1990,1990 to 2000, 2000 to 2010 and 1980 to 2010, as shown in Fig. 4, respectively. Baseline was created landward using the buffer method with manual modification in the $100 \mathrm{~m}$ extension of the coastlines of the Bohai Rim in four phases. The length of the baseline was $4745.54 \mathrm{~km}$. Thousands of transects were then casted along the coastline at a space of $1 \mathrm{~km}$ with their orientation perpendicular to the baseline. We calculated the coastline change distance based on the intersection points of each transect and coastlines. Results showed that from 1980 to 2010, areas with obvious coastline changes were mainly distributed in the Bohai Bay-Yellow River Deltasouth coast of Laizhou Bay and the north coast of Liaodong Bay. Among the periods 1980-1990, 1990-2000, and 2000-2010, the distances of coastline changes in the Bohai Rim were consistent with those from 1980 to 2010 in distribution.

\section{Analysis of the causes of the coastline changes}

In order to analyze the causes of the coastline changes in detail, firstly, we analyzed some related social-economic indicators, Table 2. These statistical data came from some authorized magazines, such as "China Marine Statistical
Yearbook" and "China Statistical Yearbook". As shown in Table 2, since China's Reform and Opening in 1978, the Bohai Rim stepped into a fast growth stage of economy and society with large population density and economic aggregate. The Gross Regional Product of Bohai Rim sharp increased from 90.5 billion yuan in 1980-8724.6 billion yuan in 2010. The land connects the water at coastal zone, where the mariculture, salt industry and port transportation developed extremely rapidly. From 1980 to 2010, mariculture areas increased drastically; total area of salt pan increased continuously with a relatively slow growth; the cargo handled at coastal seaports increased by $246,15210^{4} \mathrm{t}$ with a trend of accelerating growth.

Then, the range of coastline dynamics in each studied period was calculated by overlaying the coastlines of two adjacent phases. This information suggests various anthropogenic activities and natural factors that caused coastline changes in different periods using the visual interpretation method in combination with remote sensing images. According to the results, the anthropogenic activities that caused coastline changes from 1980 to 2010 mainly included the reclamation of aquaculture ponds, salt fields, cultivated fields, harbor, construction and transportation; natural factors causing coastline change were mainly sedimentation and erosion.

As shown in Table 3, from 1980 to 2010, the land area in the Bohai Rim had a net increase of $2583.2 \mathrm{~km}^{2}$, mainly due to anthropogenic development and partially due to estuary siltation. The coastal area of $2789.7 \mathrm{~km}^{2}$ have been 

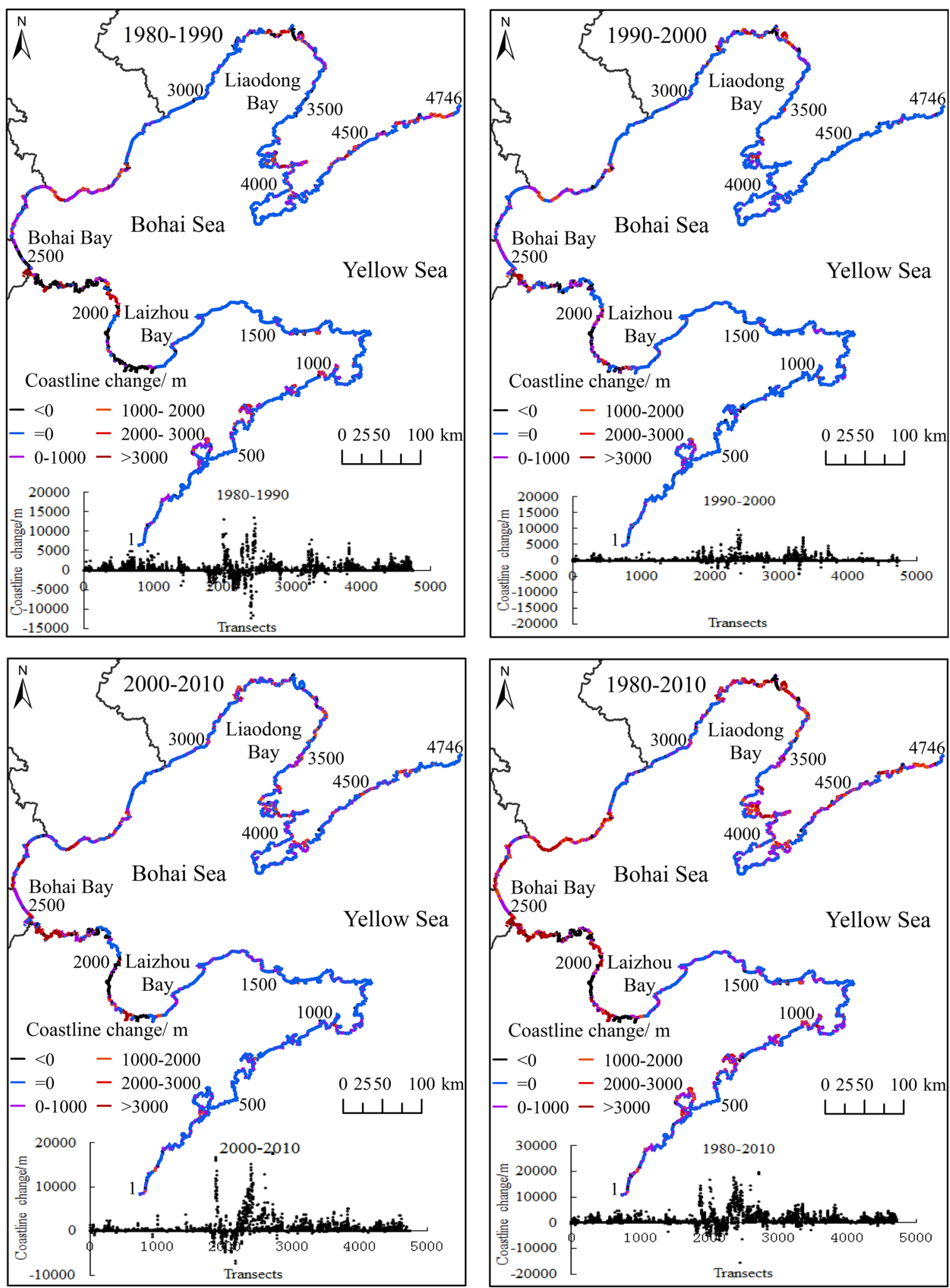

Fig. 4 Distribution of the spatial change distance of coastlines between 1980 and 2010

reclaimed for satisfying the economic and industrial demand. As coasts were eroded, $554.9 \mathrm{~km}^{2}$ of lands were lost. Eroded coasts were mainly located on both sides of the Yellow River Estuary. The area of aquaculture ponds was $1100.7 \mathrm{~km}^{2}$, which was the greatest, followed by $630.5 \mathrm{~km}^{2}$ for harbor construction and $630.2 \mathrm{~km}^{2}$ for salt 
Table 2 Some social-economic indicators of Bohai Rim in 1980, 1990, 2000 and 2010

\begin{tabular}{lrrrr}
\hline & \multicolumn{1}{c}{1980} & \multicolumn{1}{c}{1990} & \multicolumn{1}{c}{2000} & \multicolumn{1}{c}{2010} \\
\hline Population $/ 10^{4}$ persons & 16,700 & 19,436 & 21,062 & 22,456 \\
Gross regional product $/ 10^{8}$ yuan & 905 & 3438 & 19,940 & 87,246 \\
Mariculture areas $/ \mathrm{hm}^{2}$ & 267,889 & $1,042,763$ & $4,552,890$ & $6,620,857$ \\
Total area of Salt Pan $/ \mathrm{hm}^{2}$ & 177,043 & 238,861 & 294,860 & 380,783 \\
Cargo handled at coastal seaports $/ 10^{4} \mathrm{t}$ & 9728 & 19,512 & 48,975 & 255,880 \\
\hline
\end{tabular}

Table 3 Various activities leading to coastline change in the Bohai $\mathrm{Rim} / \mathrm{km}^{2}$

\begin{tabular}{|c|c|c|c|c|}
\hline & \multicolumn{4}{|c|}{ Land use area $/ \mathrm{km}^{2}$} \\
\hline & 1980-1990 & 1990-2000 & 2000-2010 & Subtotal \\
\hline Cultivated field & 27.6 & 15.6 & 3.3 & 46.5 \\
\hline Salt field & 156.3 & 201 & 272.9 & 630.2 \\
\hline Aquaculture pond & 557.6 & 161.2 & 381.9 & 1100.7 \\
\hline Harbor & 21 & 34.4 & 575.1 & 630.5 \\
\hline Construction & 113 & 41.4 & 207.3 & 361.7 \\
\hline Transportation & 2.6 & 0.1 & 6.4 & 9.1 \\
\hline Land-tied island & 4.2 & 0 & 14.7 & 18.9 \\
\hline Sedimentation & 174.6 & 106.5 & 48.2 & 329.4 \\
\hline Other & 1.4 & 13.5 & 0.2 & 15.2 \\
\hline Harbor mining & 0 & -2.4 & -1.7 & -4.2 \\
\hline Erosion & -299.3 & -69.7 & -185.8 & -554.9 \\
\hline Total & 759.1 & 501.7 & 1322.4 & 2583.2 \\
\hline
\end{tabular}

fields. The factors affecting coastline change had significant temporal heterogeneity. Before 2000, coastal development was mainly constituted by the reclamation of aquaculture and salt fields in which the speed of the development slowed from 1990 to 2000, while from 2000 to 2010 , the factors causing coastal change tended to become diversified and the rates of harbor reclamation and construction increased. Various construction projects and the expansion of coastal engineering mainly caused the coastlines to extend seaward, while projects that caused the coastlines to retreat landward were rare.

Due to anthropogenic development, the replacement of winding muddy coastlines by the reclamation of aquaculture and the sea reclamation that occurred in some bays are the two main causes of the decrease in the coastline length. Harbors, construction and the convex reclamation of aquaculture ponds resulted in an increase in the coastline; in addition, some neritic islands were developed and connected to the mainland directly, which formed new coastlines and increased the total length of the coastline. As for natural factors, sediment deposition in estuaries and sandbank extension also extended the total length of the coastline. For example, sediment deposition in the Yellow River Estuary formed new land. Factors such as river migration, sea sediment reduction, an increase in the marine dynamic effect and hydrocratic motion will cause coastal erosion, resulting in a reduction in the length of the coastline.

Thus, coastal areas were obviously affected by local economic development compared with anthrogenic activities, natural processes, such as estuary sedimentation and erosion, exerted relatively smaller effects on the coastlines in the research area.

\section{Discussion}

According to the analysis above, the main reason for coastal change in the Bohai Rim over the past 30 years was anthropogenic development, while natural factors were secondary reasons. The coastline types on each coast were significantly different due to different landforms. The Bohai Bay-Yellow River Delta-south coast of Laizhou Bay and the north coast of Liaodong Bay were the areas with the most acute changes in the Bohai Rim. The total baseline length of the two coasts was $1387.77 \mathrm{~km}$, accounting for $29.24 \%$ of the total baseline length. However, as the coastlines changed, the land area increased by $2098.19 \mathrm{~km}^{2}$, accounting for $66.77 \%$ of the new land area in the Bohai Rim.

As shown in Fig. 5, the coastlines of the Bohai BayYellow River Delta-south coast of Laizhou Bay area showed the greatest change. The substrate of the coasts mainly consists of mud silt, followed by sands. The Yellow River Delta is one of the most active deltas in the world. An alternate evolution of sedimentation and erosion resulted in a high rate of land formation and frequency of downstream migration in the Yellow River Estuary (Ye et al. 2007). In 1996, the Yellow River Estuary was rechanneled. When sedimentation in the new estuary generated land, the old areas began to erode. In addition, artificial reclamation of aquaculture ponds and salt fields caused acute decreases in muddy coastlines; in the northwest portion of Bohai Bay (from the Tianjin to the Caofeidian), the coastlines changed sharply from 2000 to 2010 and was mainly caused by the expansion of harbor construction due to needs for rapid economic development.

The total length of the coastlines in this area was 1159.6, 1175.5, 1303.3 and $1549.4 \mathrm{~km}$ in 1980, 1990, 2000 and 
Fig. 5 Coastline change in the Bohai Bay-Yellow River Deltasouth coast of Laizhou Bay

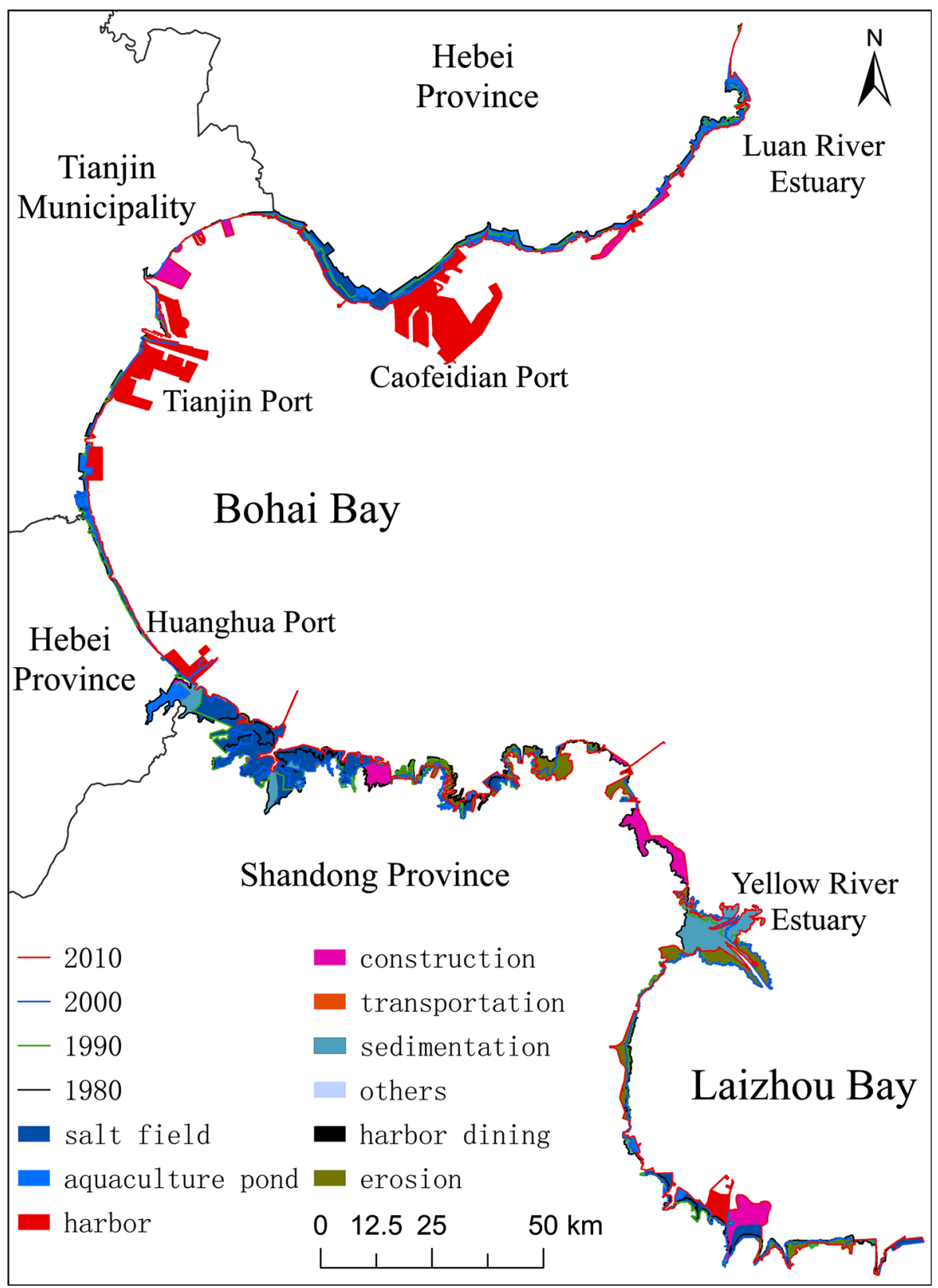

2010, respectively. Over the past 30 years, the coastlines increased rapidly by $389.8 \mathrm{~km}$. The proportion of artificial coastlines increased from $21.1 \%$ of the total length in 1980 to $82.2 \%$ in 2010 .

Differences in the land areas and coastline types during various periods of coastline change were significant. The area of new land from 1980 to 1990 was $479.7 \mathrm{~km}^{2}$, of which natural sedimentation, aquaculture ponds and construction made the greatest contributions; the area of new land from 1990 to 2000 was $330.7 \mathrm{~km}^{2}$, of which salt fields, natural sedimentation and aquaculture ponds made the greatest contributions. The area of new land from 2000 to 2010 was $979.7 \mathrm{~km}^{2}$, and the land was mainly used for harbor construction, salt fields and construction.

The type of coastal area led to significant driving factors of coastline change. From 1980 to 1990, natural sedimentation, reclamation of aquaculture and construction were the main factors; from 1990 to 2000, salt fields, aquaculture ponds and natural sedimentation were the main factors; from 2000 to 2010, harbor construction became significantly more important and became a leading factor in coastal development.

As shown in Fig. 6, this coastal area was located on the north coast of Liaodong Bay, where the substrate mainly 
consisted of silt. The coastline in this area changed acutely and is concentrated on both sides of the estuaries of the Shuangtaizi River and the Daliao River. The large-scale development of Liaodong Bay began in the 1980s. In 1980, the length of artificial coastlines accounted for $24.4 \%$ of the total coastline length. After 1980, the length of artificial coastlines increased sharply and by 2010 had reached a proportion of $94.4 \%$. Under the comprehensive influences of anthropogenic development and land-sea interactions, from 1980 to 2010, the length of the coastline increased by $71.1 \mathrm{~km}$. Coastline change during different phases generated new land with a similar area. The area of new land from 1980 to 1990 was $89.89 \mathrm{~km}^{2}$, of which aquaculture ponds, cultivated fields and natural sedimentation made the greatest contributions; the area of new land from 1990 to 2000 was $99.34 \mathrm{~km}^{2}$, of which aquaculture ponds, salt fields and cultivated fields made the greatest contributions; and the area of new land from 2000 to 2010 was $86.51 \mathrm{~km}^{2}$, of which aquaculture, harbor construction and construction made the greatest contributions.

The driving factors of coastline change were also significantly different in coastal areas. From 1980 to 1990, cultivated fields and natural sedimentation were the main factors; from 1990 to 2000, the reclamation of aquaculture salt fields and cultivated fields were the main factors; and from 2000 to 2010, the harbor construction became significantly more important and aquaculture ponds remained an important part of coastal development.

Human interference is neither worldwide in extent nor uniform regionally (Zhang et al. 2004). In recent year, few large-scale reclamation were constructed in the world except for China, Singapore, Japan and United Arab Emirates, etc. In contrast, coastlines tend to retreat worldwide, with over 70 percent of the world's beaches experiencing coastal erosion (Bird 1996). The main driving factors are sea level rises, storm surges and unreasonable human activities (Cai et al. 2009). Coastal erosion has increasingly become a major concern for future socio-economic development in coastal cities. A sea level rise caused by global warming will reduce a seawall's protective capability. Society must learn to live with a rapidly evolving coastline which is increasingly prone to flooding from tropical cyclones (Woodruff et al. 2013).

These changes in coastline, whether natural or manmade, affects wetland ecosystem and socio-economic developments (Sridhar et al. 2009). Dynamic monitoring of coastline variation remains a research focus. Studies focused on causes and mechanisms of coastline changes and its' eco-environmental effects of various coastal zones, as well as on the characteristics of interrelations and interaction of different regions, are one of the priorities for future research on global coastline changes.

\section{Conclusion}

This paper focuses on the long-term change analysis of Bohai Rim coast utilizing Remote Sensing and GIS techniques for the detection of coastline movement that changes over time in response to economic, social, and environmental forces. Since know how about the changes can to facilitate rational planning, scientific management, and suitable regulation of coastal zones. The main conclusions were as follows.

The length and component of coastline changed dramatically in the Bohai Rim during 1980-2010. The total length of the coastline in the Bohai Rim increased by

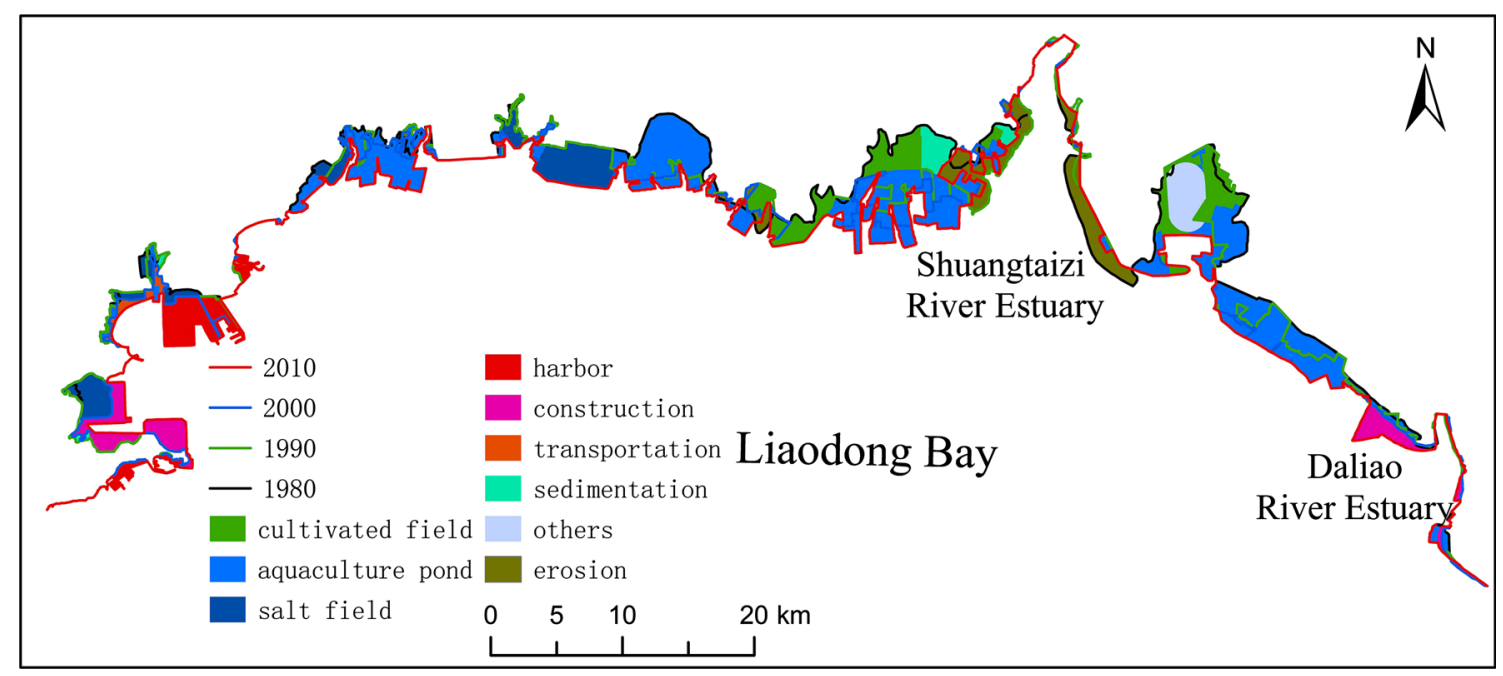

Fig. 6 Coastline change on the north coast of Liaodong Bay 
$1071.3 \mathrm{~km}$. Furthermore, the coastline artificial trend is clear, while the natural coastline disappears acutely.

The coastline of the Bohai Rim advanced to the sea with acute coastline changes and uneven change rates as well as obvious differences in the coastline changes. The Bohai Bay, the south and west coast of the Laizhou Bay and the north coast of Liaodong Bay showed the greatest changes.

The factors affecting coastline change had significant temporal heterogeneity and anthropogenic development activities are a leading factor. After 2000, a coastal reclamation is mainly focuses on port transportation and urban construction, while before 2000, focuses on salt field and aquaculture pond.

In principle, the accuracy of the coastline detection depends on the spatial resolution of the source data. The higher the spatial resolution, the higher the accuracy of the detected coastline. Due to the spatial resolution of the source data, there is a certain deviation in the visual interpretation results. But in general, the monitoring results can truly reflect the real scale and trend of coastline change in the Bohai Rim.

Acknowledgments This work was supported from Basic Special Program of Ministry of Science and Technology (2014FY210600), Strategic Priority Research Program of the Chinese Academy of Sciences (XDA11020702), Key Research Program of the Chinese Academy of Sciences (KZZD-EW-14), Talent Fund of Yantai Institute of Coastal Zone Research and Science and Technology Science and Technology Project of Yantai (2014ZH085).

\section{References}

Alesheikh AA, Ghorbanali A, Nouri N (2007) Coastline change detection using remote sensing. Int $\mathrm{J}$ Environ Sci Tech 4(1):61-66

Bird ECF (1996) Beach management: coastal morphology and research. Wiley, Chichester

Boak EH, Turner IL (2005) Shoreline definition and detection: a review. J Coastal Res 21(4):688-703

Cai F, Su XZ, Liu JH, Li B, Lei G (2009) Coastal erosion in China under the condition of global climate change and measures for its prevention. Prog Nat Sci 19(4):415-426

Gao Y, Wang H, Su FZ, Liu GM (2013) Spatial and temporal of continental coastline of China in recent three decades. Acta Oceanol Sin 35(6):31-42 (in Chinese)

Gens R (2010) Remote sensing of coastlines: detection, extraction and monitoring. Int J Remote Sens 31(7):1819-1836

Guo LY, Wang DL, Qiu JJ, Wang LG, Liu Y (2009) Spatio-temporal patterns of land use change along the Bohai Rim in China during 1985-2005. J Geogr Sci 19:568-576

Heo J, Kim JH, Kim JW (2009) A new methodology for measuring coastline recession using buffering and non-linear least squares estimation. Int J Geogr Inf Sci 23(9):1165-1177

Hou XY, Wu T, Wang YD, Xu XL, Chen Q, Yu LJ (2014) Extraction and accuracy evaluation of multi-temporal coastlines of mainland China since 1940s. Mar Sci 38(11):66-73 (in Chinese)
Kim DJ, Moon WM, Park SE, Kim JE, Lee HS (2007) Dependence of waterline mapping on radar frequency used for sar images in intertidal areas. IEEE Geosci Remote S 4(2):269-273

Lee JS, Jurkevich I (1990) Coastline detection and tracing in SAR images. IEEE T Geosci Remote 28(4):662-668

Li RX, Ma RJ, Di KC (2002) Digital tide-coordinated shoreline. Mar Geod 25:27-36

Liu H, Jwzek KC (2004) Automated extraction of coastline from satellite imagery by integrating canny edge detection and locally adaptive thresholding methods. Int $\mathrm{J}$ Remote Sens 25(5):937-958

Ma XF, Zhao DZ, Xing XG, Zhang FS, Wen SY, Yang F (2007) Means of withdrawing coastline by remote sensing. Mar Environ Sci 26(2):185-189 (in Chinese)

Moore LJ (2000) Shoreline mapping techniques. J Coast Res 16(1):111-124

Muslim AM, Foody GM (2008) Dem and bathymetry estimation for mapping a tide-coordinated shoreline from fine spatial resolution satellite sensor imagery. Int J Remote Sens 29(15):4515-4536

Office of the State Oceanic Administration 908 Special (OSOA) (2005) Regulations of coastal investigation techniques. China Ocean Press, Beijing, pp 1-2

Ryu JH, Won JS, Kyung KD (2002) Waterline extraction from landsat TM data in a tidal flat a case study in Gomso Bay. Korea Remote Sens Environ 83(3):442-456

Sesli FA, Karsli F, Colkesen I, Akyol N (2009) Monitoring the changing position of coastlines using aerial and satellite image data: an example from the eastern coast of Trabzon, Turkey. Environ Monit Assess 153:391-403

Sridhar RS, Elangovan K, Suresh PK (2009) Long term shoreline oscillation and changes of Cauvery delta coastline inferred from satellite imageries. J Indian Soc Remote 37(1):79-88

Sun WF, Ma Y, Zhang J, Liu SW, Ren GB (2011) Study of remote sensing interpretation keys and extraction technique of different types of shoreline. Bull Surv Mapp 3:41-44 (in Chinese)

Sun XY, Lü TT, Gao Y, Fu M (2014) Driving force analysis of Bohai Bay coastline change from 2000 to 2010. Resour Sci 36(2):413-419 (in Chinese)

Thieler ER, Himmelstoss EA, Zichichi JL, Ergul A (2009) Digital Shoreline Analysis System (DSAS) version 4.0-an arcgis extension for calculating shoreline change, US Gegeological Survey Open-File Report 2008, p 1278

Turner RK (2000) Integrating natural and socio-economic science in coastal management. J Mar Syst 25(3):447-460

Woodruff JD, Irish JL, Camargo SJ (2013) Coastal flooding by tropical cyclones and sea-level rise. Nature 504(7478):44-52

Xu JY, Zhang ZX, Zhao XL, Wen QK, Zuo LJ, Wang X, Yi L (2014) Spatial and temporal variations of coastlines in northern China (2000-2012). J Geogr Sci 24(1):18-32

Ye QH, Chen SL, Huang C, Xue YC, Tian GL, Chen SP, Shi YN, Liu QS, Liu GH (2007) The graph characteristics of landscape information of the modern Yellow River Tail swing and its subdelta body development. Sci China Ser D Earth Sci 37(6):813-823 (in Chinese)

Zhang KQ, Douglas BC, Leatherman SP (2004) Global warming and coastal erosion. Clim Change 64(1-2):41-58

Zhu GR, Xu XG (2012) Annual processes of land reclamation from the sea along the northwest coast of Bohai Bay during 1974-2010. Scientia Geographica Sinica 32(8):1006-1012 (in Chinese)

Zhu XH, Wang J, Chen X (2001) Study on the spatial fractal characteristic of coastline, a case study of Jiangsu Province. China Scientia Geographica Sinica 21(1):70-75 (in Chinese) 